\title{
OPTIMASI PARAMETER MESIN 3D BIOPRINTER DENGAN RESPONSE SURFACE METHOD
}

\author{
Kartinasari Ayuhikmatin Sekarjati ${ }^{1}$, Andrean Emaputra ${ }^{2}$, Alva Edy Tontowi ${ }^{3}$ \\ Jurusan Teknik Industri, Fakultas Teknologi Industri, Institut Sains \& Teknologi AKPRIND \\ Jl. Kalisahak No. 28, Klitren, Gondokusuman, Yogyakarta, 55222, Indonesia ${ }^{1,21}$ \\ Jurusan Teknik Industri, Fakultas Teknik, Universitas Gadjah Mada \\ Jl. Grafika No. 2, Sinduadi, Mlati, Sleman, Yogyakarta, 55281, Indonesia ${ }^{3)}$ \\ E-Mail : sekar@akprind.ac.id ${ }^{1)}$,andrean.emaputra@akprind.ac.id ${ }^{2}$, alvaedytontowi@ugm.ac.id ${ }^{3)}$
}

\begin{abstract}
ABSTRAK
Penelitian ini menggunakan material polymethylmethacrylate (PMMA) dan hydroxyapatite (HA). Rasio komposisi PMMA : MMA = $1: 1$ dengan rasio komposisi hydroxyapatite (HA) terhadap PMMA powder 0,50:1 (w/w). Rasio komposisi tersebut akan dicetak melalui mesin 3D Bioprinter yang memiliki nozzle 1,5 mm. Parameter proses mesin 3D Bioprinter yang akan diteliti yaitu parameter perimeter speed dengan rentang $20 \mathrm{~mm} / \mathrm{s}, 30 \mathrm{~mm} / \mathrm{s}$ dan $40 \mathrm{~mm} / \mathrm{s}$, parameter infill speed dengan rentang $50 \mathrm{~mm} / \mathrm{s}, 60 \mathrm{~mm} / \mathrm{s}$, dan $70 \mathrm{~mm} / \mathrm{s}$, dan parameter fill density dengan rentang $40 \mathrm{~mm} / \mathrm{s}$, $50 \mathrm{~mm} / \mathrm{s}$ dan $60 \mathrm{~mm} / \mathrm{s}$. Parameter-parameter tersebut dilakukan optimasi menggunakan response surface method dengan software Minitab 17. Desain spesimen yang akan dicetak melalui mesin 3D Bioprinter untuk pengukuran dimensi dan uji kuat tarik menggunakan ASTM D638 Type 1. Hasil penelitian ini menunjukkan bahwa titik optimal terdapat pada titik $31,15 \mathrm{~mm} / \mathrm{s}$ untuk parameter perimeter speed, di titik 58,84 mm/s untuk parameter infill speed dan di titik $64 \%$ untuk parameter fill density. Dimana untuk ukuran dimensi dilakukan penambahan pada desain digital dengan skala 1 : 1,02 mm untuk dimensi panjang, skala $1: 1,08 \mathrm{~mm}$ untuk dimensi lebar, skala 1:1,09 mm untuk dimensi lebar narrow dan skala $1: 1,17 \mathrm{~mm}$ untuk dimensi tebal.
\end{abstract}

Kata kunci: Mesin 3D Bioprinter; Polymethylmethacrylate (PMMA); Hydroxyapatite (HA); Response Surface Method; Akurasi Dimensi

\section{PARAMETER OPTIMIZATION OF 3D BIOPRINTER MACHINE WITH RESPONSE SURFACE METHOD}

\begin{abstract}
This research uses material polymethylmethacrylate (PMMA) and hydroxyapatite (HA). The composition of PMMA: MMA is 1: 1 with the ratio composition of HA to PMMA powder is 0.50: 1 $(w / w)$. The composition will be printed with a $3 D$ Bioprinter that has $1.5 \mathrm{~mm}$ nozzle. The parameters of the $3 D$ Bioprinter's tested are perimeter speed with a range of $20 \mathrm{~mm} / \mathrm{s}, 30 \mathrm{~mm} / \mathrm{s}$ and $40 \mathrm{~mm} / \mathrm{s}$, infill speed with a range of $50 \mathrm{~mm} / \mathrm{s}, 60 \mathrm{~mm} / \mathrm{s}$, and $70 \mathrm{~mm} / \mathrm{s}$, and fill density with a range of $40 \mathrm{~mm} / \mathrm{s}$, $50 \mathrm{~mm} / \mathrm{s}$ and $60 \mathrm{~mm} / \mathrm{s}$. These parameters were optimized using response surface method with Minitab software 17. The design of specimens to be printed with a 3D Bioprinter machine using ASTM D638 Type 1. This design will be tested with dimensional measurement and tensile strength. The result of this study is indicated the optimal point at $31.15 \mathrm{~mm} / \mathrm{s}$ for the perimeter speed's parameter, 58.84 $\mathrm{mm} / \mathrm{s}$ for the infill speed's parameter and $64 \%$ for the fill density's parameter. Dimension of the design is added with a scale of 1: $1.02 \mathrm{~mm}$ for length's dimensions, 1: $1.08 \mathrm{~mm}$ for width's dimensions, 1: $1.09 \mathrm{~mm}$ for narrow width's dimensions and 1: $1.17 \mathrm{~mm}$ for thick's dimensions.
\end{abstract}

Keywords: 3D Bioprinter Machine; Polymethylmethacrylate (PMMA); Hydroxyapatite (HA); Response Surface Method; Dimensional Measurement 


\section{PENDAHULUAN}

Kerusakan dari struktur tulang manusia dapat diatasi dengan berbagai alternatif solusi. Penggantian struktur tulang (implan tulang) memiliki tujuan untuk memperbaiki, memelihara dan mengganti struktur tulang yang rusak akibat penyakit, kecelakaan, dan trauma (Anjarsari et al., 2016). Material dasar yang digunakan pada bidang medis untuk implan tulang adalah biomaterial. Jenis dari biomaterial ini yaitu biokeramik, biopolymer, biokomposit, dan biologam (Anwar dan Solechan, 2014) yang dapat digunakan untuk meningkatkan fungsi tubuh (Kim, 2015).

Beberapa tahun terakhir ini terdapat perkembangan untuk perbaikan struktur tulang manusia dengan bantuan tulang sintesis (Lieshout et al., 2011). Material yang sering digunakan pada bidang medis yaitu komposit berbahan dasar polymethylmetacrylate (PMMA) (Puska et al., 2011 dan Zebarjad et al., 2011).

Polymethylmethacrylate (PMMA) adalah salah satu material medis yang sering digunakan dalam penelitian. Material ini memiliki sifat biokompatibilitas. Penelitian terkini memperlihatkan bahwa peningkatan minat terhadap material PMMA untuk pembuatan obat-obatan pada bidang medis (Amer, 2014).

PMMA murni memiliki sifat mekanis yang terbatas, kurang kompatibel, kaku, dan non-bioaktif (Zebarjad et al., 2011). Dalam rencana penelitian ini, PMMA murni akan dicampurkan dengan hydroxyapatite (HA). HA memiliki kelebihan yang mampu mengatasi kekurangan PMMA murni. HA banyak digunakan sebagai material implan tulang, karena memiliki sifat yang biocompatibel, bioresorbable, osteokonduktif (Anjarsari et al., 2016), nontoxic, dan bioaktif (Fathi et al., 2008). Menurut Gergely et al. (2010), HA bersifat bioaktif yang mendukung pertumbuhan tulang dan osteokonduktif ketika diaplikasikan pada ortopedik seperti gigi atau rahang. HA dapat dijadikan alternatif sebagai material implan tulang, material HA memiliki ikatan osteoblas yang akan membentuk jaringan tulang baru (Anjarsari et al., 2016). Penelitian Asdi dan Kaelani (2013), menggunakan material HA sebagai material utama. Penelitian ini dilakukan untuk mengetahui laju keausan dari material hydroxyapatite (HA) dan polymethylmethacrylate (PMMA) serta mekanisme keausan yang terjadi pada permukaannya untuk diaplikasikan pada prosthesis.

Eksperimen mengenai ini telah dilakukan sebelumnya oleh beberapa peneliti terkait penentuan parameter proses yang optimal. Pada masa terkini telah dikembangkan mesin $3 \mathrm{D}$ printing sebagai media pencetakan biokomposit (spesimen). Perkembangan ini memiliki tujuan agar hasil cetakan lebih akurat dan dapat membantu permasalahan medis dalam hal pencetakan implan tulang yang lebih kompleks. Menurut Mohamed et al. (2015) teknologi manufaktur yang paling popular dan memiliki sifat additive untuk berbagai aplikasi teknik adalah Fused Deposition Modelling (FDM). Proses FDM dikenalkan secara komersial pada awal 1990-an oleh Stratasys Inc, USA. Jurnal ini memiliki tujuan untuk meninjau penelitian lain dalam menentukan dan mengoptimalkan parameter proses FDM. Hasil yang didapatkan melalui proses FDM memiliki kualitas yang tergantung pada parameter. Dengan demikian, identifikasi parameter FDM secara signifikan mempengaruhi kualitas hasil dari proses FDM.

Penelitian terkait mesin 3D Printing dilakukan Tontowi et al. (2017) untuk mencari komposisi optimal melalui material polymethylmethacrylate

(PMMA), hydroxyapatite (HA), dan sericin. Rasio komposisi dari powder PMMA:liquid MMA yaitu sebesar 2 : 1.8, konsentrasi hydroxyapatite (HA) sebesar $10 \%$ dari powder PMMA dan sericin sebesar $0.32 \%$ dari hydroxyapatite (HA). Metode yang digunakan yaitu response surface method untuk memodelkan dan mengoptimalkan parameter. Titik optimal yang diperoleh untuk mendapatkan galat dimensi terkecil 
yaitu pada kombinasi parameter perimeter speed sebesar $113.6 \mathrm{~mm} / \mathrm{s}$, infill speed sebesar $124.1 \mathrm{~mm} / \mathrm{s}$, dan layer height sebesar $0.2 \mathrm{~mm}$. Sedangkan untuk mendapatkan kuat tarik tertinggi yaitu pada kombinasi parameter perimeter speed sebesar 113.6 $\mathrm{mm} / \mathrm{s}$, infill speed sebesar $130.9 \mathrm{~mm} / \mathrm{s}$, dan layer height sebesar $0.6 \mathrm{~mm}$. Dan untuk mendapatkan galat dimensi terkecil dan kuat tarik tertinggi yaitu pada kombinasi perimeter speed sebesar $102.8 \mathrm{~mm} / \mathrm{s}$, infill speed sebesar $126.1 \mathrm{~mm} / \mathrm{s}$, dan layer height sebesar $0.2 \mathrm{~mm}$.

Penelitian Tontowi et al. (2017), dilakukan kembali untuk melihat pengaruh dari parameter proses lainnya terhadap hasil cetak melalui mesin 3D Printing. Parameter yang diteliti yaitu layer thickness, temperature dan raster angle dengan 2 level. Metode yang digunakan untuk mengoptimalkan ketiga parameter tersebut adalah metode response surface dan taguchi. Design of experiment (DoE) didapatkan dengan metode response surface. Sedangkan setting parameter optimum didapatkan melalui metode taguchi. Material filamen PLA akan dicetak dengan mesin 3D Printing.

Penelitian sebelumnya akan menjadi dasar untuk penelitian ini dalam melakukan eksperimen terkait penentuan optimasi parameter yang optimal dengan material PMMA dan peningkatan konsentrasi hydroxyapatite (HA) hingga $70 \%$ jika dibandingkan dengan penelitian yang telah dilakukan oleh Tontowi et al. (2017). Parameter yang akan diteliti yaitu perimeter speed, infill speed dan fill density. Optimasi parameter yang optimal akan ditentukan dengan response surface method. Material PMMA dan hydroxyapatite (HA) akan dicetak dengan mesin 3D Bioprinter yang memiliki nozzle lebih kecil dari $2 \mathrm{~mm}$. Spesimen hasil cetakan akan diuji galat dimensi.

Penelitian yang dilakukan oleh Tontowi et al. (2017) dengan material yang sama, konsentrasi HA terhadap PMMA powder adalah 10\%, dan rasio komposisi PMMA:MMA yaitu 2:1.8 (w/v). Konsentrasi HA pada penelitian tersebut tidak sesuai dengan bobot yang terkandung pada tulang manusia. Konsentrasi HA pada sebagian besar tulang manusia adalah 60-70\% dari tiap bobot kering (Boskey, 2013). Oleh karena itu, dalam rencana penelitian ini konsentrasi HA ditingkatkan hingga $70 \%$ pada rasio komposisi PMMA.

Penelitian ini akan mencetak material menggunakan mesin 3D Printing berjenis mesin 3D Bioprinter yang dimiliki oleh Laboratorium Desain dan Pengembangan Produk (Bioceramics), Departemen Teknik Mesin dan Industri, Fakultas Teknik, Universitas Gadjah Mada. Mesin 3D Printing ini mengalami pengembangan secara berkala, namun hasil yang didapatkan belum sesuai dengan kebutuhan. Dimana hasil cetakan belum sesuai dengan ukuran dan bentuk dari desain digital.

Berdasarkan hasil dari study awal terkait rasio komposisi PMMA yang mengandung konsentrasi hydroxyapatite (HA), dapat dilihat pada Gambar 1.

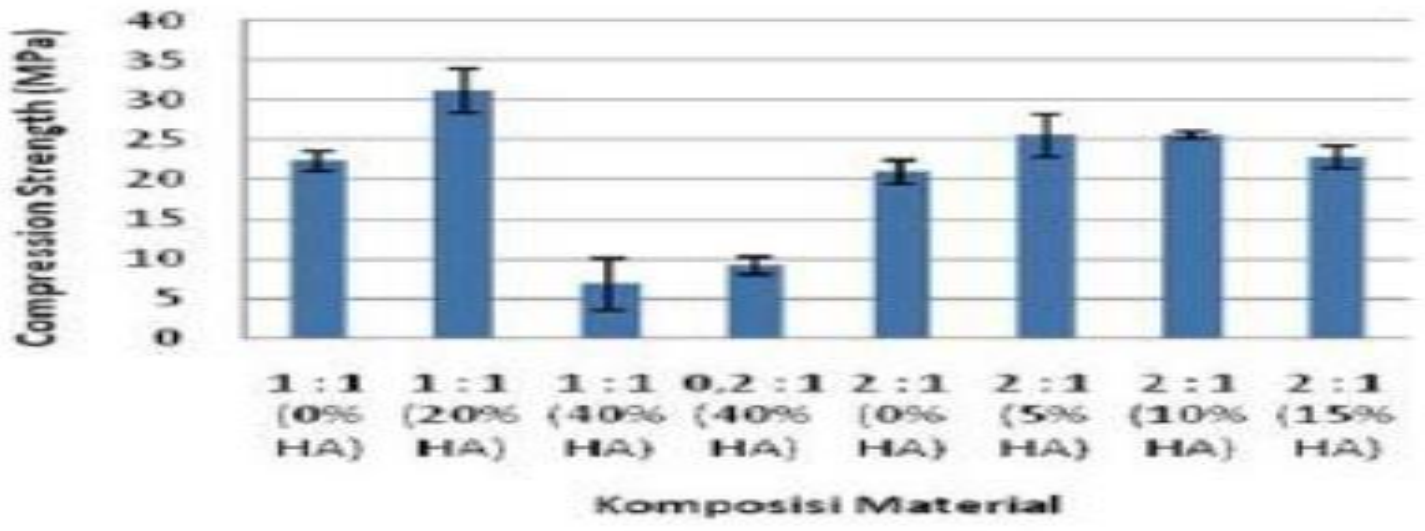

Gambar 1. Grafik Compressive Strength (Sekarjati dan Tontowi, 2018) 
Pada Gambar 1 terlihat pada rasio komposisi PMMA : MMA yaitu $1: 1(\mathrm{w} / \mathrm{v})$ dengan konsentrasi hydroxyapatite (HA) sebesar $20 \%$ terhadap total campuran, merupakan komposisi yang memiliki compressive strength tertinggi. Jika konsentrasi hydroxyapatite (HA) tersebut diubah menjadi rasio komposisi hydroxyapatite (HA) terhadap PMMA powder, maka rasio tersebut menjadi $0.50: 1$ (w/w).

Oleh karena itu, dalam rencana penelitian ini komposisi tersebut akan menjadi input mesin 3D Bioprinter. Tujuan dari penelitian ini yaitu diharapkan dari hasil printing, menghasilkan cetakan spesimen yang memiliki kesamaan geometri dengan desain digital. Jika diaplikasikan pada struktur tulang manusia, ukuran dimensi dari hasil printing dapat sesuai dengan ukuran dari struktur tulang yang mengalami kerusakan.

Dalam proses printing komposit campuran PMMA dan hydroxyapatite (HA) memerlukan optimasi parameter proses mesin 3D Bioprinter. Menurut Mohamed et al. (2015), ada beberapa parameter proses (working parameter) yang mempengaruhi kualitas dari spesimen hasil cetakan dan kekuatan spesimen. Parameter tersebut yaitu air gap, raster angle, raster width, part interior style, layer thickness, part fill style, part $x, y, z$ shrinkage factor, dan contour width.

Namun, parameter mesin 3D Bioprinter yang mampu disetting adalah parameter fill density, infill speed, perimeter speed, layer height, fill angle dan perimeter. Parameter yang dipilih untuk diteliti lebih lanjut yaitu parameter perimeter speed (kecepatan proses printing bagian luar, bergerak secara vertikal dan horizontal pada sumbu $\mathrm{X}$ dan $\mathrm{Y}$ ), parameter infill speed (kecepatan proses printing bagian dalam yang bergerak secara diagonal pada sumbu $\mathrm{X}$ dan $\mathrm{Y}$, pada setiap layer pergerakannya saling berpotongan dengan layer sebelumnya), dan parameter fill density. Parameter ini dipilih karena diduga berpengaruh terhadap akurasi dimensi dan kekuatan mekanik. Parameter belum dilakukan optimasi, sehingga dalam rencana penelitian ini parameter tersebut perlu diteliti lebih lanjut agar memperoleh hasil cetakan yang sesuai dengan desain digital.

\section{METODOLOGI}

Pada eksperimen ini dibuat spesimen ASTM D638 Type 1.

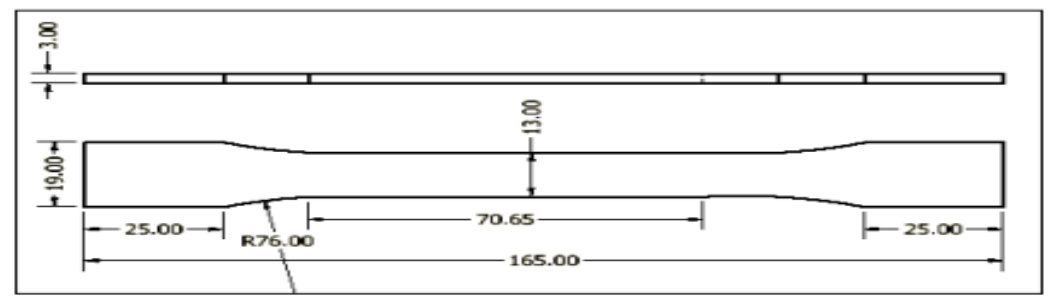

Gambar 2. ASTM D638 Type 1

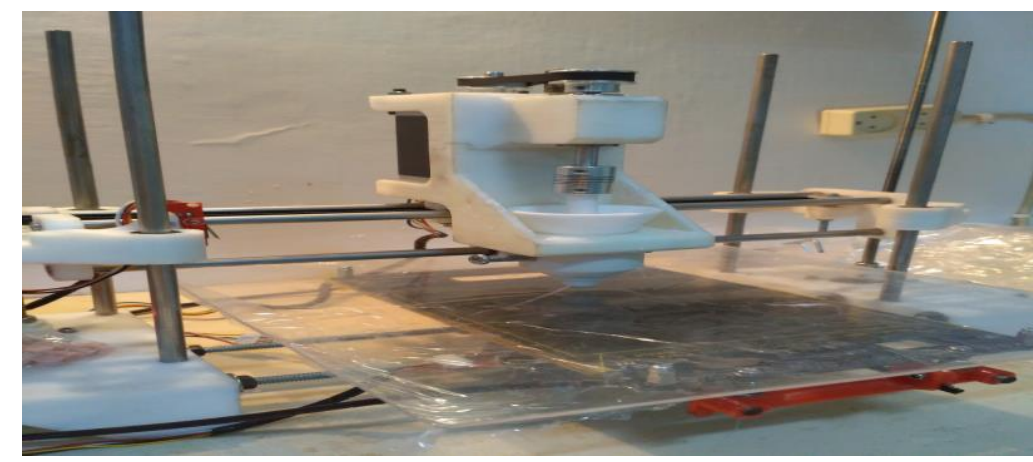

Gambar 3. Mesin 3D Bioprinter 
Spesimen terbuat dari material polimetilmetakrilat (PMMA) berbentuk powder dan metilmetakrilat (MMA) berbentuk cair, (ISO 1567 Type I Class 1, Acrylic Denture Materials), serta material hidroksiapatit (HA), (Bio-nano karbonat, BATAN) yang berasal dari sisik ikan. Powder polymethylmethacrylate (PMMA) yang digunakan pada penelitian ini yaitu jenis heat curing, karena material ini mampu melewati mesin 3D Bioprinter. Sedangkan powder polymethylmethacrylate (PMMA) jenis self curing tidak mampu melewati mesin 3D Printing karena memiliki waktu solidifikasi yang pendek (Utami, 2016).

Mesin yang digunakan untuk penelitian ini yaitu mesin 3D Bioprinter seperti Gambar 3. Mesin tersebut dibuat secara manual. Part mesin tersebut, terdiri dari 12 kerangka besi, 1 meja kaca yang terhubung dengan 1 meja penggerak, mesin dan penyangga mesin dibuat melalui proses printing dengan menggunakan material PLA, dan kabel - kabel sebagai penghantar listrik. Mesin 3D Bioprinter tersebut terhubung dengan software Pronterface, yang berfungsi sebagai setting parameter mesin. Dalam penelitian ini akan dilakukan optimasi terhadap parameter mesin. Optimasi ini dilakukan dengan tujuan agar menghasilkan spesimen yang sesuai dengan desain digital.

Ada beberapa metode optimasi yang digunakan, antara lain taguchi method, genetic algorithms (GA), artificial neural networks (ANN), factorial design dan response surface method (RSM) (Mohamed et al., 2015). Dalam rencana penelitian ini, metode response surface method (RSM) dipilih untuk optimasi parameter mesin 3D Bioprinter. Metode ini memiliki kelebihan yang mampu menjelaskan efek dari interaksi antara variabel - variabel, dan metode ini menghasilkan prediksi yang akurat jika dibandingkan dengan metode lainnya.
Persamaan response surface method (RSM) pada orde satu, yaitu (Bradley, 2007)

$y=\beta_{0}+\beta_{1} x_{1}+\beta_{2} x_{2}+\varepsilon$

dengan,

$\mathrm{y}=$ Variabel response.

$\beta_{0}=$ Nilai prediksi pada model regresi.

$\beta_{1}=$ Nilai dari variabel explanatory (faktor 1).

$\beta_{2}=$ Nilai dari variabel explanatory (faktor 2).

$x_{1}=$ Faktor 1 yang diteliti dalam eksperimen (variabel explanatory).

$x_{2}=$ Faktor 2 yang diteliti dalam eksperimen (variabel explanatory).

$\varepsilon=$ Error pada model regresi.

Selanjutnya, persamaan response surface method (RSM) pada orde dua, yaitu (Bradley, 2007) :

$y=\beta_{0}+\beta_{1 x_{1}}+\beta_{2 x_{2}}+\beta_{11 x_{1}}{ }^{2}+\beta_{22} x_{2}^{2}+$ $\beta_{12} x_{1} x_{2}$

dengan,

$\mathrm{y}=$ Variabel response.

$\beta_{0}=$ Nilai prediksi pada model regresi.

$\beta_{1}=$ Nilai dari variabel explanatory (faktor 1).

$\beta_{11}=$ Nilai dari variabel explanatory (faktor 1) quadratic.

$\beta_{12}=$ Nilai dari variabel explanatory (faktor 1 dan faktor 2) quadratic.

$\beta_{2}=$ Nilai dari variabel explanatory (faktor 2).

$\beta_{22}=$ Nilai dari variabel explanatory (faktor 2) quadratic.

$x_{1}=$ Faktor 1 yang diteliti dalam eksperimen (variabel explanatory).

$x_{2}=$ Faktor 2 yang diteliti dalam eksperimen (variabel explanatory).

$x_{1} x_{2}=$ Faktor 1 (variabel explanatory) dan faktor 2 (variabel explanatory) yang diteliti dalam eksperimen (quadratic). 
$x_{I}^{2}=$ Faktor 1 (variabel explanatory) yang diteliti dalam eksperimen (quadratic).

$x_{2}{ }^{2}=$ Faktor 2 (variabel explanatory) yang diteliti dalam eksperimen (quadratic). $\varepsilon=$ Error pada model regresi.
Dalam melakukan optimasi, maka dibentuk design of experiment (DOE) berdasarkan metode response surface method (RSM). DOE yang dibentuk melalui software Minitab 17, dapat dilihat melalui Tabel 1. Tahapan penelitian ditunjukkan pada Gambar 4.
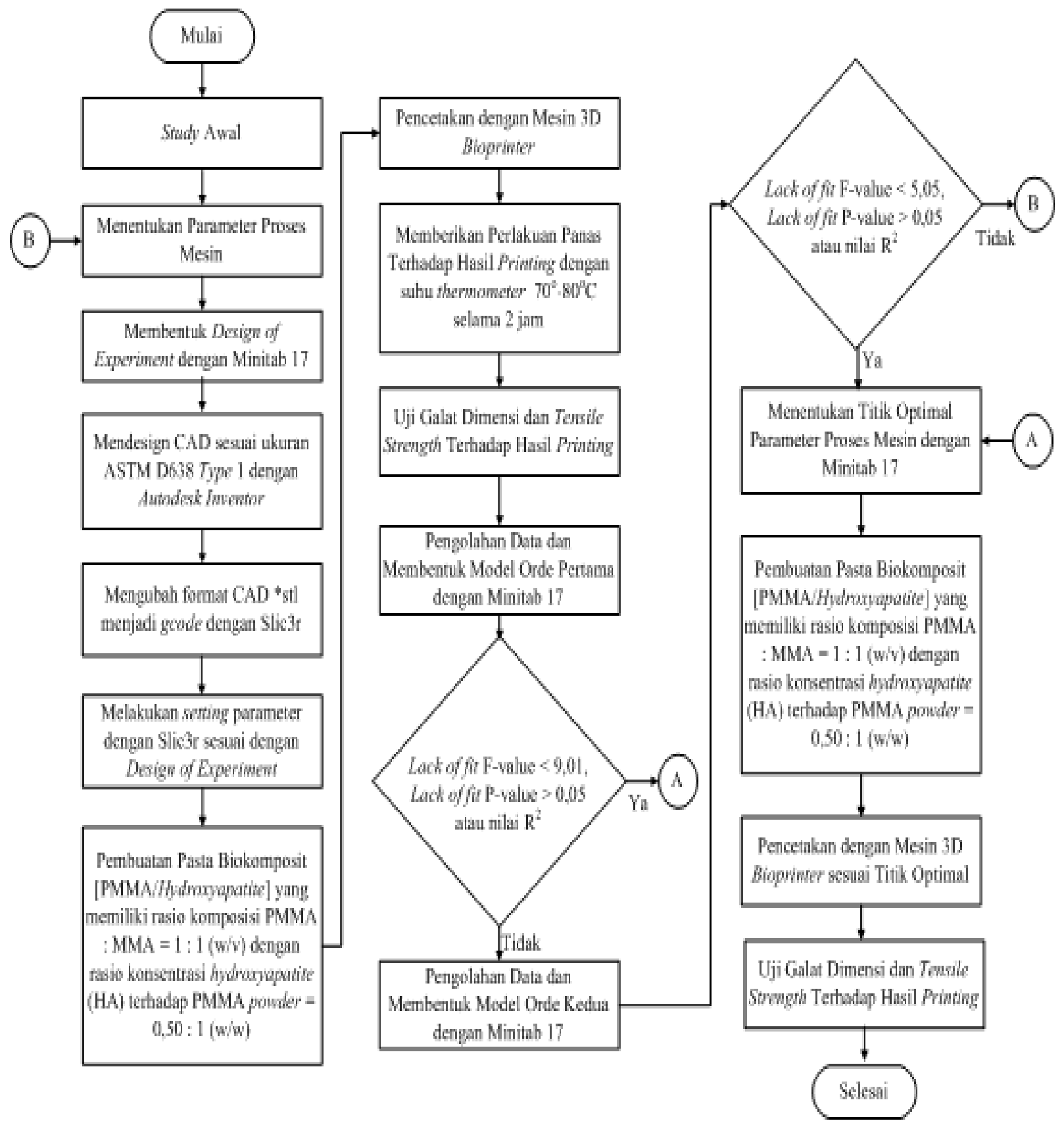

Gambar 4. Tahapan Penelitian 
Tabel 1. Design of Experiment (DOE)

\begin{tabular}{ccccccc}
\hline \multirow{2}{*}{$\mathrm{RT}$} & \multicolumn{3}{c}{ Coded Variable } & \multicolumn{3}{c}{ Actual Variable } \\
\cline { 2 - 7 } & $\mathrm{X} 1$ & $\mathrm{X} 2$ & $\mathrm{X} 3$ & $\mathrm{X} 1$ & $\mathrm{X} 2$ & $\mathrm{X} 3$ \\
\hline 1 & 1 & -1 & 1 & 40 & 50 & 60 \\
2 & -1 & 1 & -1 & 20 & 70 & 40 \\
3 & 0 & 0 & 0 & 30 & 60 & 50 \\
4 & 0 & 0 & 0 & 30 & 60 & 50 \\
5 & 0 & 0 & 0 & 30 & 60 & 50 \\
6 & -1 & -1 & -1 & 20 & 50 & 40 \\
7 & -1 & 1 & 1 & 20 & 70 & 60 \\
8 & 0 & 0 & 0 & 30 & 60 & 50 \\
9 & 1 & -1 & -1 & 40 & 50 & 40 \\
10 & 1 & 1 & -1 & 40 & 70 & 40 \\
11 & -1 & -1 & 1 & 20 & 50 & 60 \\
12 & 1 & 1 & 1 & 40 & 70 & 60 \\
13 & 0 & -1.633 & 0 & 30 & 43.67 & 50 \\
14 & 0 & 0 & 0 & 30 & 60 & 50 \\
15 & 0 & 0 & 1.633 & 30 & 60 & 66.33 \\
16 & 1.633 & 0 & 0 & 46.33 & 60 & 50 \\
17 & -1.633 & 0 & 0 & 13.67 & 60 & 50 \\
18 & 0 & 0 & -1.633 & 30 & 60 & 33.67 \\
19 & 0 & 0 & 0 & 30 & 60 & 50 \\
20 & 0 & 1.633 & 0 & 30 & 76.33 & 50 \\
\hline
\end{tabular}

3. HASIL DAN PEMBAHASAN

Curing time window untuk komposisi PMMA : MMA = 1 : 1 dengan komposisi hydroxyapatite (HA) terhadap PMMA powder $0.50: 1$ (w/w) yaitu 400-1000 detik. Curing time window dimulai dari campuran biokomposit [PMMA / Hydroxyapatite] saat pasta stage, lalu diinputkan ke mesin 3D Bioprinter sampai dough stage. Proses printing dilakukan ketika pasta stage sampai dough stage atau sampai campuran biokomposit [PMMA / Hydroxyapatite] keluar melewati nozzle (Tontowi et al., 2017). Namun, pada pilot Study yang telah dilakukan komposit ini tidak mampu menyatu dan sulit untuk dicetak pada menit ke 13 (750 detik). Oleh karena itu, proses printing lebih baik dilakukan pada detik ke 400-750.

Pengumpulan data dilakukan dengan 12 eksperimen melalui rancangan 2 faktorial dan ditambah dengan 4 titik pusat (center point). Rancangan ini berasal dari output Minitab 17. Penelitian ini menggunakan 3 faktor yaitu perimeter speed, infill speed dan fill density. Sedangkan response dari penelitian ini adalah persentase nilai galat dimensi.

Menurut Bradley (2007), uji kecukupan data dilakukan melalui uji normalitas dan uji lack of fit. Hasil uji normalitas dari masingmasing response telah dianalisis sebelumnya dengan melihat nilai P-value dari hasil output software Minitab 17. Melalui analisis tersebut, data yang diperoleh telah dapat diasumsikan normal. Selanjutnya akan dilakukan uji lack of fit terhadap masingmasing response.

Uji lack of fit akan dilakukan terlebih dahulu pada orde satu. Optimasi dilakukan dengan response surface method dan digambarkan dengan garis linier.

Melalui pengolahan dengan menggunakan software Minitab 17, model regresi respon galat dimensi panjang yang diperoleh adalah:

$$
\begin{aligned}
& \bar{y}_{p}=0.0030-0.000020 P S-0.000016 I S+ \\
& 0.000125 F D .
\end{aligned}
$$


Model regresi respon galat dimensi lebar yang diperoleh adalah:

$\overline{\mathrm{y}}_{l}=0.038+0.00018 P S+0.00544 I S-$ $0.00261 F D$.

Model regresi respon galat dimensi lebar narrow yang diperoleh adalah:

$\overline{\mathrm{y}}_{l n}=0.040-0.00001 P S+0.00682 I S-$ $0.00030 F D$.

Model regresi respon galat dimensi tebal yang diperoleh adalah:

$\overline{\mathrm{y}}_{t}=0.384+0.00268 P S-0.00239 I S-$ $0.00189 F D$.

dengan,

$\overline{\mathrm{Y}}=$ Nilai prediksi untuk respon variabel.

$\mathrm{PS}=$ Nilai untuk kode variabel perimeter speed.

IS = Nilai untuk kode variabel infill speed .

$\mathrm{FD}=$ Nilai untuk kode variabel fill density .

Eksperimen pada orde satu yang telah dilakukan ini telah menggambarkan model dengan baik, karena telah memenuhi syaratsyarat seperti nilai $\mathrm{F}$ yang berada dibawah $\mathrm{F}$ tabel semua dan nilai $\mathrm{P}$ yang berada diatas nilai $\alpha$ semua. Namun, untuk nilai koefisien determinasi $\left(\mathrm{R}^{2}\right)$ pada masing - masing model regresi masih relatif kecil, yang menyebabkan hubungan antara variabel bebas dan variabel respon memiliki hubungan yang rendah pada model regresi yang terbentuk. Oleh karena itu, perlu analisis tambahan ke orde dua (model quadratic) agar nilai koefisien determinasi $\left(\mathrm{R}^{2}\right)$ yang terbentuk dapat meningkat.

Data response yang didapatkan melalui proses pencetakan spesimen pada tiap run test orde dua ini akan dilakukan uji kecukupan data juga seperti pada orde satu. Menurut Bradley (2007), uji kecukupan data dilakukan melalui uji normalitas dan uji lack of fit. Hasil dari masing - masing response akan dianalisis dengan bantuan Minitab 17.
Melalui pengolahan dengan menggunakan software Minitab 17, model regresi respon galat dimensi panjang yang diperoleh adalah:

$\bar{y}_{p}=0.020-0.00097 P S+0.00070 I S-$ $0.00079 F D-0.000008 P S * P S+0.000011$ $I S * I S+0.000001 F D * F D+0.000009 P S$ $* I S+0.000017 P S * F D+0.000006 I S^{*} F D$.

Model regresi respon galat dimensi lebar yang diperoleh adalah:

$$
\begin{aligned}
& \bar{y}_{l}=3.58-0.0814 P S-0.0742 I S-0.0057 \\
& F D+0.001295 P S * P S+0.000605 I S * I S \\
& +0.000274 F D * F D+0.000487 P S * I S- \\
& 0.000507 P S * F D-0.000151 I S * F D .
\end{aligned}
$$

Model regresi respon galat dimensi lebar narrow yang diperoleh adalah:

$$
\begin{aligned}
& \bar{y}_{l n}=7.54-0.1265 P S-0.1410 I S-0.0577 \\
& F D+0.002178 P S * P S+0.000976 I S * I S \\
& +0.000783 F D * F D+0.000769 P S * I S- \\
& 0.001006 P S * F D+0.000154 I S * F D .
\end{aligned}
$$

Model regresi respon galat dimensi tebal yang diperoleh adalah:

$\overline{\mathrm{y}}_{t}=-3.121+0.0314 P S+0.0492$ IS + $0.0617 F D-0.000238 P S * P S-0.000238$ $I S * I S-0.000447 F D * F D-0.000241 P S$ * IS + $0.000000 P S * F D-0.000315 I S *$ $F D$

Pada pengolahan dan analisa orde dua, terlihat bahwa adanya pengaruh antara variabel bebas dan variabel response. Pengaruh tersebut bersifat kuat dan sangat kuat. Pada varibel response galat dimensi lebar dan lebar narrow, memiliki pengaruh dari parameter perimeter speed. Sedangkan varibel response galat dimensi tebal, memiliki pengaruh dari parameter fill density. Jika dilihat dari waktu printing pada orde dua, terdapat waktu printing yang ekstrem. Hal ini berpengaruh karena waktu printing tidak berada pada time window yang merupakan salah satu karakteristik performansi dari mesin 3D Bioprinter. 
Langkah berikutnya adalah melakukan optimasi berdasarkan variabel response panjang, lebar, lebar narrow, tebal dan tensile strength dengan bantuan software Minitab 17.

Optimasi ini dilakukan untuk mengetahui pada titik mana di variabel bebas (perimeter speed, infill speed dan fill density) yang memiliki persentase galat dimensi terkecil atau dapat dikatakan dengan titik optimal. Optimasi ini ditentukan menggunakan response optimizer pada software Minitab 17.

Titik optimal terletak pada variabel bebas di titik $31.15 \mathrm{~mm} / \mathrm{s}$ untuk parameter perimeter speed, di titik $58.84 \mathrm{~mm} / \mathrm{s}$ untuk parameter infill speed dan di titik 64\% untuk parameter fill density. Pada optimization plot terdapat nilai composite desirability yang berarti bahwa seberapa ideal kombinasi variabel yang dibentuk untuk keseluruhan response yang telah dilakukan optimasi. Nilai composite desirability ini berkisar antar 0 sampai 1. Nilai composite desirability yang terbentuk yaitu 0.6776. Jika dilihat dari nilai yang terbentuk, nilai tersebut mendekati angka 1. Nilai ini berarti kombinasi yang dihasilkan ideal. Prediksi variabel response dari titik - titik optimal ini membentuk nilai galat dimensi panjang sebesar 0.0109 , nilai galat dimensi lebar sebesar 0.1014, nilai galat dimensi lebar narrow sebesar 0.2979, dan nilai galat dimensi tebal sebesar 0.1848 .

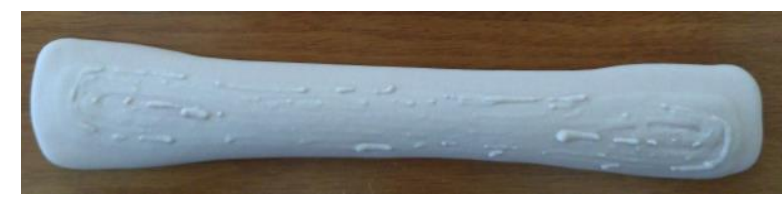

Gambar 6. Spesimen Hasil Printing

\section{KESIMPULAN}

Proses pencetakan berdasarkan hasil pengolahan software Minitab 17 dengan metode response surface didapatkan parameter mesin yang optimal pada titik $31.15 \mathrm{~mm} / \mathrm{s}$ untuk parameter perimeter speed, di titik $58.84 \mathrm{~mm} / \mathrm{s}$ untuk parameter infill speed dan di titik $64 \%$ untuk parameter fill density. Dimana untuk ukuran dimensi dilakukan penambahan pada desain digital dengan skala 1 : $1.02 \mathrm{~mm}$ untuk dimensi panjang, skala $1: 1.08 \mathrm{~mm}$ untuk dimensi lebar, skala $1: 1.09 \mathrm{~mm}$ untuk dimensi lebar narrow dan skala $1: 1.17 \mathrm{~mm}$ untuk dimensi tebal.

Jika dilihat dari hasil software Minitab 17, ada beberapa parameter yang mempengaruhi hasil dari spesimen terhadap respon galat dimensi, seperti parameter perimeter speed berpengaruh pada galat dimensi lebar dan galat dimensi lebar narrow, parameter fill density berpengaruh pada galat dimensi tebal.

\section{DAFTAR PUSTAKA}

Amer, Z. J. A., Ahmed, J. K. dan Abbas, S. F. (2014). Chitosan/PMMA Bioblend for Drug Release Applications. International Journal of Engineering and Technology, Vol.4, No.5, 318-324.

Anjarsari, Dahlan, K., Suptijah, P., dan Kemala, T. (2016). Sintesis dan Karakterisasi Biokomposit BCP/Kolagen Sebagai Material Perancah Tulang. Jurnal Pengolahan Hasil Perikanan Indonesia, Vol.19, No.3, 356-362.

Anwar, S. A., dan Solechan. (2014). Analisa karakteristik dan sifat mekanik Scaffold rekonstruksi mandibula dari material bhipasis calsium phospate dengan penguat cangkang kerang srimping dan gelatin menggunakan metode functionally graded material. Prosiding SNATIF $\mathrm{Ke}$-1. Universitas Muria Kudus, Fakultas Teknik, 137- 144.

Asdi, Z. R., dan Kaelani, Y. (2013). Kajian Tribologi Gesekan Antara Material Komposit Hidroksiapatit (HA) + PolymethylmMethacrylate (PMMA) dengan Ultra High Molecular Weight Polyethylene (PMMA) sebagai Prosthesis Sendi Rahang (TMJ) pada Manusia, Jurnal Teknik Pomits, Vol.2, No.1, 1-5. 
Boskey, A. L. (2013). Bone Composition: Relationship to Bone Fragility and Antiosteoporotic Drug Effects. International Bone and Mineral Society, No.447, 1-11.

Bradley, N. (2007). The Response Surface Methodology. Indiana University of South Bend, Indiana.

Fathi. M. H., Hanifi, A., Mortazavi, V. (2008). Preparation dan bioactivity evaluation of bond-like Hydroxyapatite nanopowder. Journal of Materials Processing Technology, Vol.202, 536-42.

Gergely, G., Wéber, F., Lukács, I., Illés, L., Attila, L., Tóth, Z., Horváth, Mihály, J. (2010). NanoHydroxyapatite Preparation from Biogenic Raw Materials. Central European Journal of Chemistry, Vol.8, No.2, 375-381.

Kim, S. K., Kim, Y. J., Yoon, T. L., Park, S. A., Cho, I. H., Kim, E. J., Kim, I. A., dan Shin, J. (2004). The characteristics of a Hydroxyapatitechitosan PMMA bone cement. Journal of Biomaterials, Vol.25, 5715-5723.

Lieshout, E., Kralingen, G., El-Massoudi, Y., Weinans, H., dan Patka, P. (2011). Microstructure and biomechanical characteristics of bone substitutes for trauma and orthopaedic surgery. BMC Musculoskeletal Disorders, Vol.12, No.34.

Mohamed, O. A., Masood, S. H., dan Bhowmik, J. L. (2015). Optimization of Fused Deposition Modeling Process Parameter a Review of Current Research and Future Prospects. Advances in Manufacturing, Vol.4, 42-53.
Puska, M., Aho, A.J., Vallittu, P. (2011). Polymer Composites for Bone Reconstruction. INTECH Open Access Publisher.

Sekarjati, K. A., dan Tontowi, A. E. (2018). The Composition of Biocomposite [Polymethylmethacrylate/Hydroxya patite] As Material For Specimen With Portabee Kit Machine. Jurnal Sinergi, Vol.22, No.3, 169-176.

Tontowi, A. E., Anggraeni, D., Saragih, H. TSSG., Raharjo, K. P. N., dan Utami, P. (2017). Experimental Study of 3D-printable Biocomposite of [HA/PMMA/Sericin] materials. Advance Materials Letters, Vol.8, No.8, 857-861.

Utami, P. (2016). Optimasi Parameter Proses Ekstrusi Pasta Biokomposit [PMMA/Hidroksiapatit/Serisin]

Pada Mesin Printer 3D Menggunakan Metode Response Surface. Skripsi. Universitas Gadjah Mada.

Zebarjad, S.M., Sajjadi, S.A., Sdrabadi, T.E., Yaghmaei, A., Naderi, B. (2011). A Study on Mechanical Properties of PMMA/Hydroxyapatite

Nanocomposite. Engineering, Vol.3, 795-801. 